\title{
Association between medical student debt and choice of specialty: a 6-year retrospective study
}

\author{
Erik M. Fritz ${ }^{1 *}$ (D), Suzanne van den Hoogenhof ${ }^{2}$ and Jonathan P. Braman ${ }^{3}$
}

\begin{abstract}
Background: The effect of rapidly increasing student debt on medical students' ultimate career plans is of particular interest to residency programs desiring to enhance recruitment, including primary care specialties. Previous survey studies of medical students indicate that amount of student debt influences choice of medical specialty. Research on this topic to date remains unclear, and few studies have included the average income of different specialties in analyses. The purpose of this study is to observe whether empirical data demonstrates an association between debt of graduating medical students and specialties into which students match.

Methods: This was a retrospective cross-sectional study of a public institution including data from graduation years 2010-2015. For each included student, total educational debt at graduation and matched specialty were obtained. Average income of each specialty was also obtained. Statistical hypothesis testing was performed to analyze any differences in average debt among specialties; subanalysis was performed assessing debt for primary care (PC) versus non-primary care (NPC) specialties. Correlation between student debt and average specialty income was also evaluated.
\end{abstract}

Results: One thousand three hundred ten students met the inclusion criteria and 178 were excluded for a final study population of 1132 (86\%). The average debt was $\$ 182,590$. Average debt was not significantly different among the different specialties $(P=0.576)$. There was no significant difference in average debt between $P C$ and NPC specialties ( $P C \$ 182,345 \pm \$ 64,457, \mathrm{NPC} \$ 182,868 \pm \$ 70,420, P=0.342)$. There was no correlation between average specialty income and graduation debt (Spearman's rho $=0.021, P=0.482$ ).

Conclusions: At our institution, student indebtedness did not appear to affect matched medical specialty, and no correlation between debt and average specialty income was observed. Different subspecialties and residency programs interested in recruiting more students or increasing diversity may consider addressing alternative factors which may have a stronger influence on student choices.

Keywords: Student debt, Career choice, Medical school, Medical students

\section{Background}

Since the middle of the twentieth century, college tuition has increased at roughly twice the rate of general inflation [1] with one study citing over a $300 \%$ increase in the cost of public medical school in the final two

\footnotetext{
* Correspondence: fritz177@umn.edu

Research Performed at the University of Minnesota Medical School, Minneapolis, MN

${ }^{1}$ Department of Orthopaedic Surgery at the University of Minnesota in Minneapolis, 2450 Riverside Avenue South, Suite R200, Minneapolis, MN 55454, USA

Full list of author information is available at the end of the article
}

decades [2]. Consequently, medical students need to utilize higher amounts of loans to finance their educations [3]. In 2015 , more than $80 \%$ of graduating medical students had educational debt [4]; of those with debt, the median total was $\$ 183,000$ [4].

However, it is unclear whether this increasing debt has implications on students' career plans. Previous studies have investigated the relationship of graduate debt on specialty choice as this is of particular interest to primary care (PC) specialties, which are projected to have a shortage of 35,000 to 44,000 providers by 2025 [5].

(C) The Author(s). 2019 Open Access This article is distributed under the terms of the Creative Commons Attribution 4.0 International License (http://creativecommons.org/licenses/by/4.0/), which permits unrestricted use, distribution, and 
Surveys of medical students report debt having an influence on specialty choice [6-11] while non-survey studies have demonstrated that debt appears to have little to no association with specialty [12-14]. Furthermore, few studies have included the average income of different specialties and the relationship this may have with debt.

To fill this gap, the present study provides an analysis of medical student debt, specialty choice, and average earnings per specialty over the past six years at our institution. The purposes of this study were to 1 ) determine whether an association exists between debt of graduating medical students and specialties into which students match, and 2) determine whether a correlation exists between indebtedness and average income of students' chosen specialty.

\section{Methods}

This was a retrospective cross-sectional study at the University of Minnesota Medical School, which is a public institution, including data from May 2010 to May 2015 utilizing the Strengthening the Reporting of Observational Studies in Epidemiology (STROBE) criteria. The Office of Student Finance provided total educational debt at graduation for each student, including both undergraduate and medical school debt. Specialty, determined from the residency match, was also obtained for each student. All personal data were de-identified prior to analysis; for further protection of privacy, specialties into which fewer than five students matched were grouped into the category, "Non-primary care: Unspecified." Average income of each specialty for each graduation year was obtained from the Medical Group Management Association Physician Compensation and Production annual survey [15-20]. Values for debt and income from different years were adjusted to present day values utilizing a $3 \%$ annual inflation rate [21].

Every student who graduated from the institution's Doctor of Medicine (M.D.) program from May 2010 to May 2015 was initially included in the study. Exclusion criteria included students for whom debt or match data were unavailable, students who did not match into an advanced or categorical program for a given year, and students who matched into a specialty into which compensation data was unavailable.

\section{Statistical methods}

Statistical analysis was performed with SPSS Statistics Version 21.0 (IBM; Armonk, NY). A KolmogorovSmirnov test showed nonparametric distribution of all data; thus, any difference in debt between the specialties was evaluated by Kruskal-Wallis test. Spearman's rho assessed correlation between average specialty income and graduation debt. Additionally, students were grouped into PC (family medicine, internal medicine, pediatrics, and combined internal medicine and pediatrics) and non-primary care (NPC) specialties; a Mann Whitney U test was used to evaluate differences in debt. Since physicians in pediatrics and internal medicine frequently subspecialize into higher-paying specialties, an additional subanalysis compared only family medicine versus NPC. To assess threshold effect, students were also grouped into $\$ 75,000$ debt quintiles as previously described by Phillips et al. [9] and chi-square analysis evaluated whether more students went into PC at a particular debt quintile. For all analyses, $P<0.05$ indicated a significant difference.

\section{Ethical approval}

Ethical approval for this study was waived by the University of Minnesota Institutional Review Board; Study Number 1510E78929, date 10/30/2015. The IRB determined the study to be exempt from review under federal guidelines 45 CFR Part 46.101(b) category \#4 EXISTING DATA; RECORDS REVIEW; PATHOLOGICAL SPECIMENS.

\section{Results}

In total, 1310 students met inclusion criteria. Of these, 178 students were removed after applying exclusion criteria, leaving a final population of 1132 (86\%) (Fig. 1). The average debt was $\$ 182,590$. Table 1 demonstrates a summary of the study population. The relative risk of matching into a nonprimary care specialty with a debt

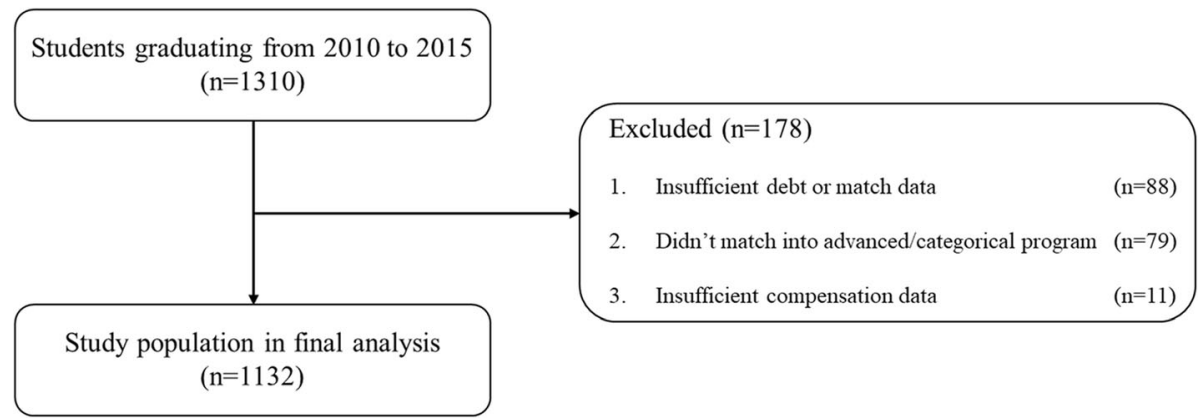

Fig. 1 Flowchart demonstrating inclusion and exclusion criteria to obtain study population 
Table 1 Summary table of study population broken down by graduation year

\begin{tabular}{llll}
\hline Year & Total Students & Average Debt (USD) & Primary Care $\mathrm{n}(\%)$ \\
\hline 2010 & 180 & 187,954 & $90(50)$ \\
2011 & 202 & 182,701 & $117(58)$ \\
2012 & 189 & 180,939 & $97(51)$ \\
2013 & 177 & 183,766 & $90(51)$ \\
2014 & 183 & 173,666 & $103(56)$ \\
2015 & 201 & 186,320 & $104(52)$ \\
Total & $\mathbf{1 1 3 2}$ & $\mathbf{1 8 2 , 5 9 0}$ & $\mathbf{6 0 1 ( 5 3 )}$ \\
\hline
\end{tabular}

greater than the mean was 1.00 (95\% confidence interval 0.02-50.40).

Amount of debt was not significantly different among different matched specialties $(P=0.576$, Fig. 2$)$. Furthermore, there was no significant difference in mean debt between PC and NPC specialties (PC \$182,345 $\pm 64,457$, NPC $\$ 182,868 \pm \$ 70,420, P=0.342$, Fig. 3). Subanalysis showed no significant difference in mean debt between students matching into family medicine versus NPC specialties (family medicine $\$ 183,569 \pm \$ 61,660$, NPC $\$ 182,868 \pm \$ 70,420, P=0.396$, Fig. 3 ).

Chi-square analysis showed no difference in students entering PC among different quintiles of debt $(P=0.112$, Table 2). Finally, there was no correlation between average specialty income and graduation debt (Spearman's rho $=0.021, P=0.482$, Fig. 4).

\section{Discussion}

The most important finding of this study is that student indebtedness at graduation did not have any association with choice of specialty. Moreover, there was no correlation between graduate debt and average income of the specialties into which students matched. This suggests that these factors appear independent even though the findings differ from numerous student survey studies [6-11].

Though medical student debt as it relates to career choice receives much interest in the published literature and media, few studies analyze empirical data obtained from offices of financial aid [12-14]. Instead, the majority of studies on this topic gather data through student

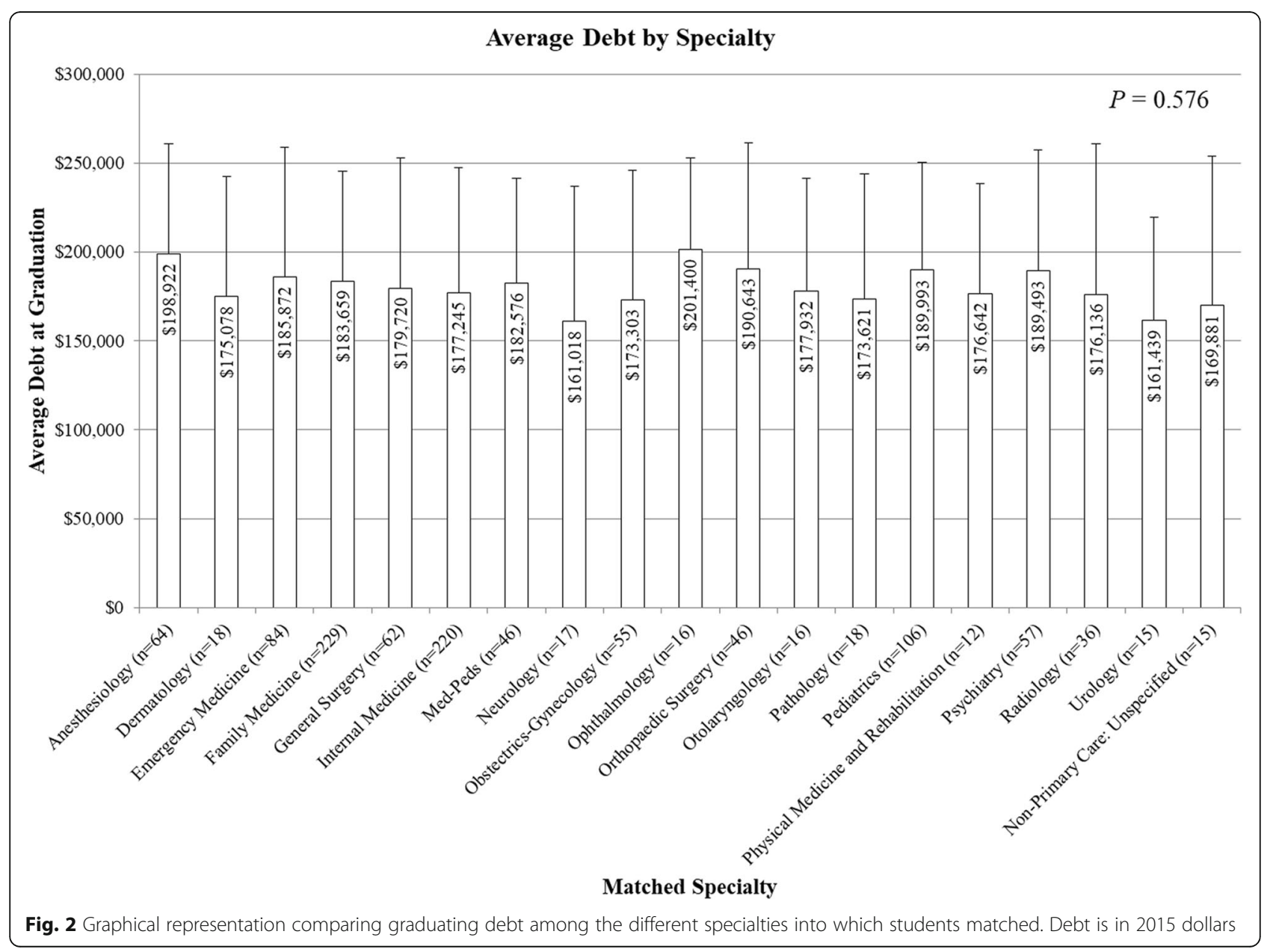




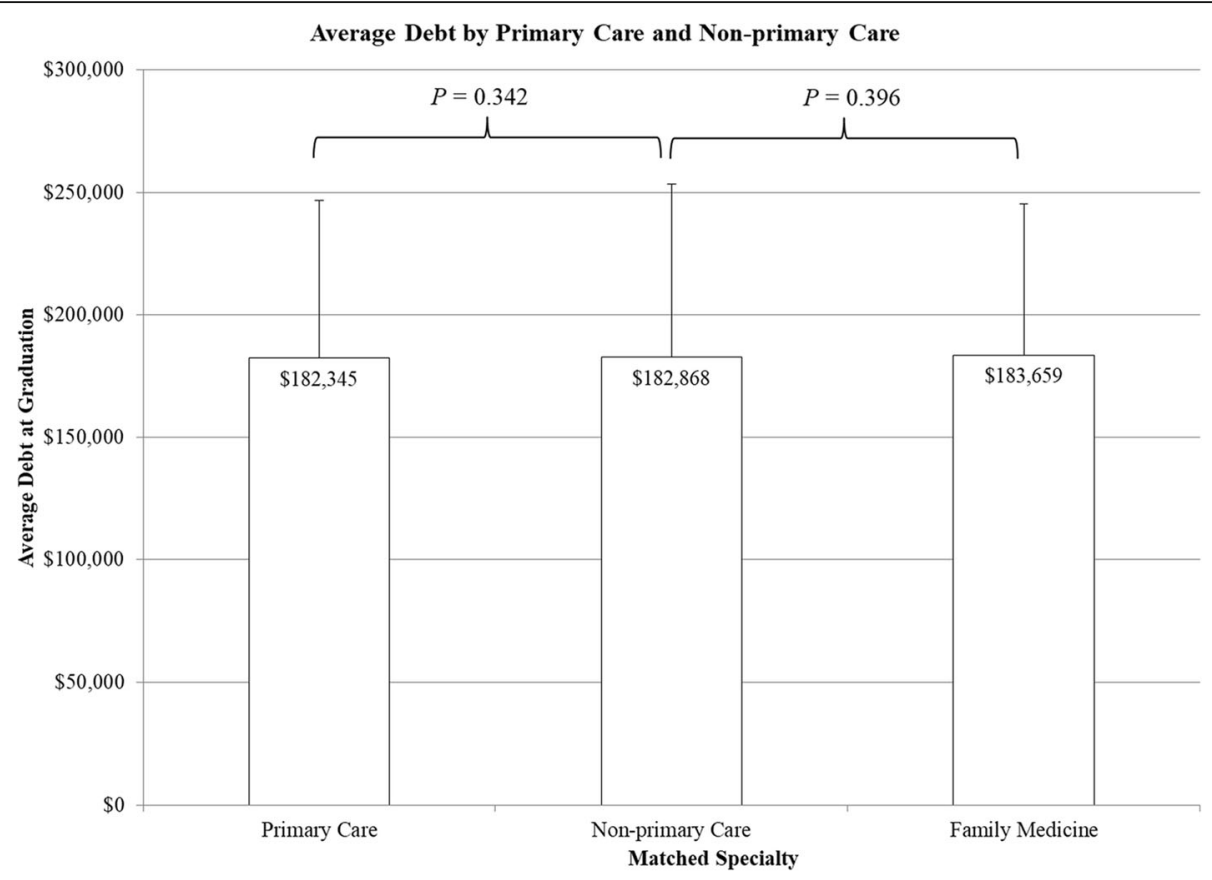

Fig. 3 Graphical representation comparing graduating debt between the primary care and non-primary care specialties into which students matched. An additional subanalysis compares debt between students matching into family practice versus non-primary care specialties. Debt is in 2015 dollars

surveys [6-11]. In 1993, Spar et al. [14] analyzed educational debt versus specialty of 1431 students who graduated between 1988 and 1990 from 6 private medical schools and found no relationship among levels of indebtedness and specialty preference [14]. By contrast, in 1996, Rosenthal et al. [13] performed a similar study analyzing 1350 students who graduated between 1987 and 1993 from Jefferson Medical College. They found that a high level of indebtedness $(>\$ 7,000)$ was a significant predictor of specialty choice away from family practice [13]. More recently, Kahn et al. [12] analyzed debt versus specialty of 2022 students who graduated between 2001 and 2005 from 3 medical schools; they found that graduates entering PC specialties did not have significantly differing debt compared to those

Table 2 Percentage of students matching into primary care versus non-primary care specialties stratified by range of student debt

\begin{tabular}{|c|c|c|c|c|}
\hline Debt Range & $\begin{array}{l}\text { Number of } \\
\text { Students }\end{array}$ & $\begin{array}{l}\text { Percent in } \\
\text { Primary } \\
\text { Care }\end{array}$ & $\begin{array}{l}\text { Percent in } \\
\text { Non-primary } \\
\text { Care }\end{array}$ & \\
\hline$\$ 0-\$ 74,999$ & 125 & $52 \%$ & $48 \%$ & \\
\hline$\$ 75,000-\$ 149,000$ & 163 & $47 \%$ & $53 \%$ & \\
\hline$\$ 150,000-\$ 224,999$ & 523 & $57 \%$ & $43 \%$ & \\
\hline$\$ 225,000-\$ 299,000$ & 308 & $50 \%$ & $50 \%$ & \\
\hline \multirow[t]{2}{*}{$\geq \$ 300,000$} & 13 & $46 \%$ & $54 \%$ & \\
\hline & & & & $P=0.112$ \\
\hline
\end{tabular}

entering other specialties, and debt was not a predictor of entering PC specialties [12]. Notably, for all three of these studies, data was obtained from the medical schools' offices of financial aid [12-14]. In general, the main findings of our study are in agreement with these aforementioned results and demonstrate that the same trend appears today, even decades later; the Rosenthal study is the exception to this. While the reason for this difference can only be speculated upon, potential explanations may include the year, the location, private versus public medical school environment, or other unidentified factors. Future prospective multi-institutional studies may further assess these variables.

Most studies analyzing student debt versus specialty obtain data through student surveys [6-11]. Kassebaum and Szenas published articles in 1992 and 1993 [6, 7] evaluating the relationship between indebtedness and specialty choice among graduating medical students using data obtained from the annual American Association of Medical Colleges (AAMC) Medical School Graduation Questionnaire (GQ). In 1992, they found only $6.2 \%$ of students cited debt as having a "strong or major influence," on specialty choice; this number nearly doubled in their 1993 study to $11.9 \%$ [6, 7]. Rosenblatt and Andrilla [11] did a similar study using the 2002 AAMC GQ; they found students with higher debt were significantly less likely to enter PC (debt $>\$ 150,000$ odds ratio 0.94). In 2014 Phillips et al. [8] analyzed the AAMC GQ for graduates from 1988 through 2000. They 
Income versus Debt
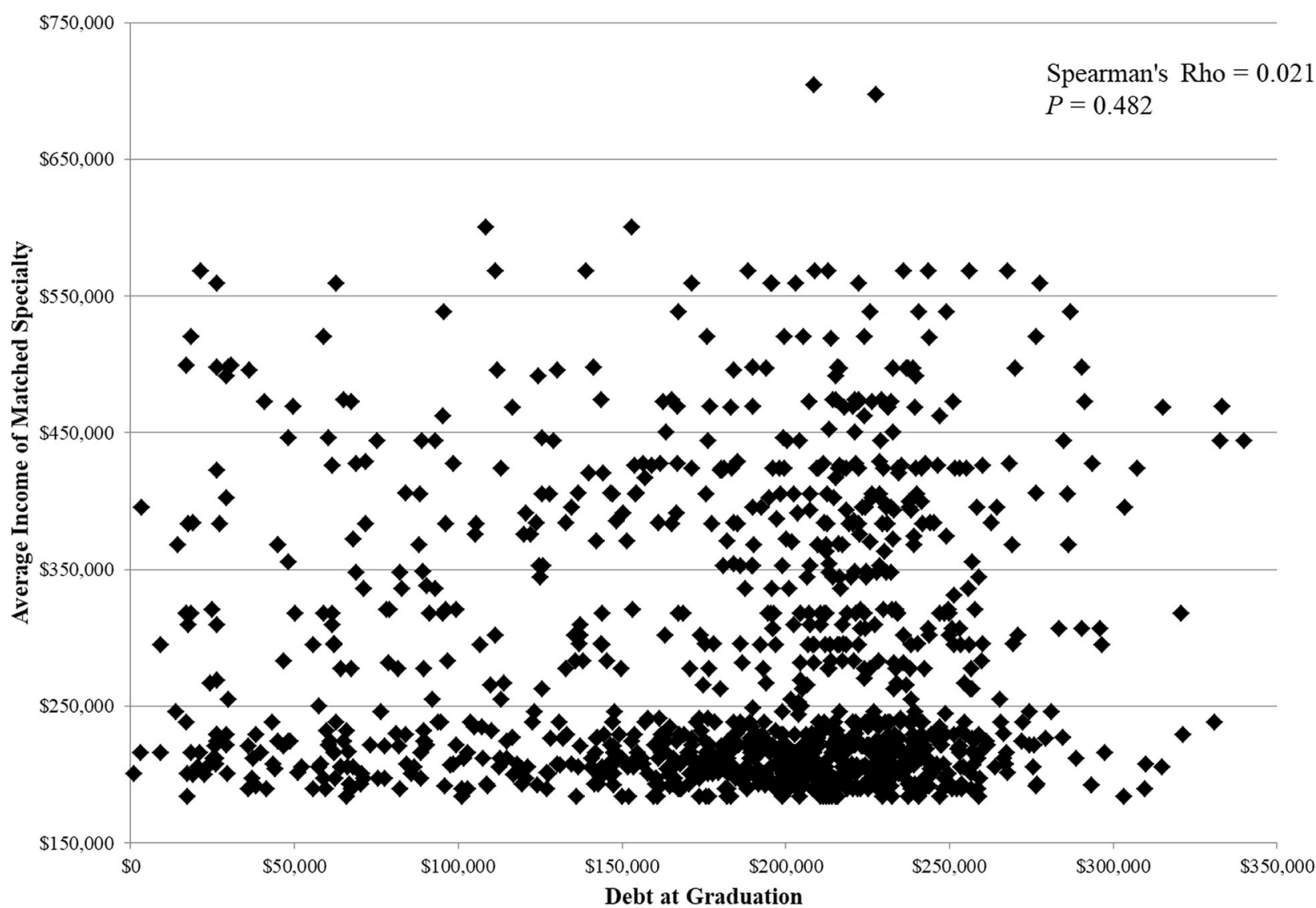

Fig. 4 Scatterplot demonstrating average income versus student debt. Each datapoint indicates the debt with which the student graduated and the average income of his or her matched specialty from that particular graduation year. Debt and income are in 2015 dollars

found physicians graduating from public schools were more likely to practice PC at debt levels of $\$ 50,000$ to $\$ 100,000$ (2010 dollars); however at higher debt levels, probability of practicing PC decreased. Likelihood of practicing $\mathrm{PC}$ did not change with debt for private school graduates [8]. Philips and colleagues [9] performed a 2010 cross-sectional survey assessing students' anticipated debt and specialty choice at three different medical schools from 2006 to 2008; when the group was analyzed as a whole, there was no relation between debt and specialty [9]. However, when stratifying family incomes, students from middle-income families anticipating more debt were less likely to plan PC careers [9]. Finally, Rohlfing et al. [10] performed an email survey of 102 medical schools with responses from 1846 students; results showed students with higher debt relative to their peers were more likely to choose a specialty with a higher income, were less likely to enter $\mathrm{PC}$, and were less likely to practice in underserved locations [10].

Our present study and these previous studies [6-14] demonstrate a notable trend. The majority of studies with empirical data from offices of financial aid (including our present study) demonstrate no relation between debt and specialty. Yet, the majority of studies with student survey data demonstrate a consistent trend of debt correlating with specialty choice. This is an interesting discrepancy which may indicate that students' perceptions of debt differ from reality; perhaps many students really believe that they cannot afford to enter primary care specialties with high indebtedness. In point of fact, Youngclaus and colleagues demonstrated that, even with very high amounts of debt, students can still affordably pursue primary care specialties [22]. Alternatively, perhaps students attribute debt as a justification for entering higher-paying specialties. Indeed, Dial and Haviland [23] argue that it should come as no surprise that the evidence has failed to establish a strong link between debt and specialty; the authors note that given the choice between a higher-paying and lower-paying specialty with similar responsibilities and working conditions, any student, regardless of debt level, would be more inclined to choose the higher paying specialty [23]. Moreover, Ebell published in both 1989 and 2008 two studies demonstrating a strong direct correlation 
between specialty incomes and residency program fill rates $(1989 r=0.85,2008 r=0.68 P=0.03)[24,25]$. This may suggest that income has a much stronger influence on specialty choice than debt. Another possibility for the discrepancy may be the concept of a threshold effect in which debt does not influence career choice until a certain threshold is reached. In our present study, we observed no such threshold effect when the data was analyzed in debt quintiles.

\section{Limitations}

There are several limitations to this study. First, we were unable to capture all debt data. Private student loans, auto loans, home loans, credit card debt, and other consumer debt were not factored into our calculations. Second, we were not able to perfectly capture career choice as some students did not match into their first-choice specialty; they may have dual-applied, gone through the supplemental offer and acceptance program, or matched in following years into a second-choice specialty. Moreover, our data does not capture plans for fellowship, which can substantially increase future income; however, we feel this limitation is addressed by our subanalysis comparing debt of those matching into family medicine versus NPC specialties. Finally, our study reflects data from a public university whereas different results may be obtained from other institutions with different student demographics, particularly private schools; this limits the generalizability of the study findings, though we feel the information can still be particularly helpful for other public institutions.

\section{Conclusion}

At our institution, student indebtedness did not appear to affect matched medical specialty, and no correlation between debt and average specialty income was observed. Different subspecialties and residency programs interested in recruiting more students or increasing diversity may consider addressing alternative factors which may have a stronger influence on student choices.

\section{Abbreviations}

NPC: Non-primary care; PC: Primary care

\section{Acknowledgements}

Not applicable.

\section{Availability of data and material}

The datasets used and/or analyzed during the current study are available from the corresponding author on reasonable request.

\section{Authors' contributions}

EF analyzed and interpreted the data and was a major contributor in writing the manuscript. SVH obtained the data. JPB was a major contributor in editing the manuscript. All authors read and approved the final manuscript.

\section{Funding}

The authors report no external funding source for this study.
Ethics approval and consent to participate

Ethical approval for this study was waived by the University of Minnesota Institutional Review Board; Study Number 1510E78929, date 10/30/2015. The IRB determined the study to be exempt from review under federal guidelines 45 CFR Part 46.101 (b) category \#4 EXISTING DATA; RECORDS REVIEW; PATHOLOGICAL SPECIMENS.

\section{Consent for publication}

Not Applicable.

\section{Competing interests}

Dr. Braman is a consultant for Zimmer, Inc. and serves as a board or committee member for the American Academy of Orthopaedic Surgeons, the American Orthopaedic Association, and the American Shoulder and Elbow Surgeons. All other authors have nothing to disclose. The remaining authors declare they have no competing interests.

\section{Author details}

${ }^{1}$ Department of Orthopaedic Surgery at the University of Minnesota in Minneapolis, 2450 Riverside Avenue South, Suite R200, Minneapolis, MN 55454, USA. ${ }^{2}$ University of Minnesota Medical School in Minneapolis, Minneapolis, MN, USA. ${ }^{3}$ Department of Orthopaedic Surgery at the University of Minnesota in Minneapolis, Minneapolis, MN, USA.

Received: 12 April 2019 Accepted: 5 September 2019

Published online: 28 October 2019

\section{References}

1. FinAid | Saving for College | Tuition Inflation [updated 2016/09/18/21:24:05]. Available from: http://www.finaid.org/savings/tuition-inflation.phtml.

2. Jolly P. Medical school tuition and young physicians' indebtedness. Health Aff (Millwood). 2005;24(2):527-35.

3. Youngclaus J, Fresne J. Association of American Medical Colleges Analysis in Brief: Trends in Cost and Debt at U.S. Medical Schools Using a New Measure of Medical School Cost of Attendance 2012 [updated 2012/07// 2016/08/ 21/06:05:06]. Available from: https://www.aamc.org/download/296002/data/ aibvol12_no2.pdf.

4. Bodenheimer T, Pham HH. Primary Care: Current Problems And Proposed Solutions. Health Aff (Millwood). 2010;29(5):799-805.

5. Kassebaum DG, Szenas PL. Relationship between indebtedness and the specialty choices of graduating medical students: 1993 update. Acad Med. 1993;68(12):934-7.

6. Phillips JP, Petterson SM, Bazemore AW, Phillips RL. A Retrospective Analysis of the Relationship Between Medical Student Debt and Primary Care Practice in the United States. Ann Fam Med. 2014;12(6):542-9.

7. Phillips JP, Weismantel DP, Gold KJ, Schwenk TL. Medical student debt and primary care specialty intentions. Fam Med. 2010;42(9):616-22.

8. Rohlfing J, Navarro R, Maniya OZ, Hughes BD, Rogalsky DK. Medical student debt and major life choices other than specialty. Med Educ Online. 2014;19:25603.

9. Rosenblatt RA, Andrilla CHA. The impact of U.S. medical students' debt on their choice of primary care careers: an analysis of data from the 2002 medical school graduation questionnaire. Acad Med. 2005;80(9):815-9.

10. Kahn MJ, Markert RJ, Lopez FA, Specter S, Randall H, Krane NK. Is Medical Student Choice of a Primary Care Residency Influenced by Debt? Medscape Gen Med. 2006;8(4):18

11. Rosenthal MP, Marquette PA, Diamond JJ. Trends along the debt-income axis: implications for medical students' selections of family practice careers. Acad Med. 1996;71(6):675-7.

12. Spar IL, Pryor KC, Simon W. Effect of debt level on the residency preferences of graduating medical students. Acad Med. 1993;68(7):570-2.

13. Medical Group Management A. MGMA physician compensation and production survey : 2010 report based on 2009 data. [Englewood, Colo.]: MGMA; 2010.

14. Medical Group Management A. MGMA physician compensation and production survey : 2011 report based on 2010 data. [Englewood, Colo.]: MGMA; 2011.

15. Medical Group Management A. MGMA physician compensation and production survey : 2012 report based on 2011 data. [Englewood, Colo.]: MGMA; 2012. 
16. Medical Group Management A. MGMA physician compensation and production survey : 2013 report based on 2012 data. In: MGMA-ACMPE. Englewood, Colo; 2013.

17. Medical Group Management A. MGMA physician compensation and production survey : 2014 report based on 2013 data. [Englewood, Colo.]: MGMA; 2014.

18. Medical Group Management A. MGMA 2015 physician compensation and production report : based on 2014 survey data. Englewood, Colo: MGMA; 2015

19. University of Michigan, University of Michigan: Inflation Expectation@ [MICH] 2016 [cited 2017 July 7]. retrieved from FRED, Federal Reserve Bank of St. Louis]. Available from: https://fred.stlouisfed.org/series/MICH.

20. Youngclaus JA, Koehler PA, Kotlikoff LJ, Wiecha JM. Can Medical Students Afford to Choose Primary Care? An Economic Analysis of Physician Education Debt Repayment. Acad Med. 2013;88(1):16-25.

21. Dial TH, Haviland MG. Money talks: why debt and specialty choice are not strongly linked. Acad Med. 1994;69(6):470.

22. Ebell MH. Choice of specialty: it's money that matters in the USA. JAMA. 1989;262(12):1630.

23. Ebell MH. Future salary and US residency fill rate revisited. JAMA. 2008; 300(10):1131-2.

24. Association of American Medical Colleges. Medical Student Education: Debt,Costs, and Loan Repayment Fact Card 2015 [updated 2015/10// 2016/ 08/21/05:16:19]. Available from: https://www.aamc.org/download/447254/ data/debtfactcard.pdf.

25. Kassebaum DG, Szenas PL. Relationship between indebtedness and the specialty choices of graduating medical students. Acad Med. 1992;67(10):700-7.

\section{Publisher's Note}

Springer Nature remains neutral with regard to jurisdictional claims in published maps and institutional affiliations.

Ready to submit your research? Choose BMC and benefit from:

- fast, convenient online submission

- thorough peer review by experienced researchers in your field

- rapid publication on acceptance

- support for research data, including large and complex data types

- gold Open Access which fosters wider collaboration and increased citations

- maximum visibility for your research: over $100 \mathrm{M}$ website views per year

At BMC, research is always in progress.

Learn more biomedcentral.com/submissions 